\title{
PHONETICS LEARNING ANXIETY - RESULTS OF A PRELIMINARY STUDY
}

\author{
MALGORZATA BARAN-LUCARZ \\ School of English, University of Wroclaw \\ mbaran-lucarz@ifa.uni.wroc.pl
}

\begin{abstract}
The main aim of this paper is to verify the assumption that pronunciation learning during a course of phonetics is hindered by the feeling of anxiety (Phonetics Learning Anxiety) experienced by foreign language (FL) learners studying English as their major at universities or colleges. A study carried out among 32 students of the School of English at Wroclaw University (Poland) revealed a significant negative correlation of moderate strength between the subjects' level of Phonetics Learning Anxiety (PhLA) and their attainments on pronunciation tests (sentence, passage and word reading) conducted after a 45-hour (30x90-minute lessons) course of practical phonetics. The detrimental effect of PhLA on pronunciation learning was further supported by t-tests, in which the pronunciation of high anxiety subjects was found to be at a significantly lower level than that of low anxiety students.

The Phonetics Learning Anxiety Scale, a 44-item questionnaire based on a 6-point Likert scale, designed for the purpose of the research sheds light on the nature of this peculiar type of apprehension experienced by advanced FL learners in a specific educational context (i.e. a traditional classroom, rather than a language or computer laboratory), in which the major focus is on pronunciation practice. The obtained quantitative data imply that such factors as fear of negative evaluation (represented by general oral performance apprehension and concern over pronunciation mistakes, pronunciation self-image, pronunciation self-efficacy and self-assessment) and beliefs about the nature of FL pronunciation learning are significant sources of PhLA. Anxiety about the transcription test (IPA Test Anxiety) - one of the other hypothetical determinants of PhLA - did not prove to be correlated with the general level of Phonetics Learning Anxiety.
\end{abstract}

Keywords: Phonetics Learning Anxiety (PhLA), pronunciation self-image, self-efficacy and self-assessment, fear of negative evaluation.

\section{Introduction}

Numerous studies examining language anxiety (LA) have proven its detrimental influence on both FL learning and performance (see Horwitz 2010). Objective data show that the feeling of apprehension experienced by students is related to their pronunciation level (e.g. Horwitz et al. 1986; Price 1991; Young 1992) and, even more strongly, to their perceived pronunciation skills (Baran-Łucarz 2011). As many learners explain (e.g. Price 1991: 105), the anxiety experienced in the FL classroom is caused mainly by their 
"great embarrassment" resulting from the belief of having a "terrible accent." Additionally, most observations reveal that the most anxiety-provoking task is oral performance in front of the whole class.

Taking into account the facts presented above, we may presuppose that a FL course of phonetics is particularly anxiety-breeding, especially when run with a group of students (rather than in the form of one-to-one tuition) in a traditional classroom (i.e. not in a computer or language laboratory). It seems that the feeling of uneasiness and worry might explain why despite high motivation to achieve native-like levels of pronunciation, predisposition for language learning, and phonetic competence, the progress of some learners is slow or hardly noticeable.

To ensure whether indeed anxiety is an important debilitative factor not allowing some students to benefit from a practical course of phonetics, and to elucidate the nature of the construct of anxiety experienced by learners during a course of phonetics, an empirical study was designed and conducted in June 2012 among first-year university students of English philology, whose results are presented in this publication.

The paper opens with a brief presentation of concepts that served as a ground for constructing the PhLAS, i.e. the concept of anxiety and language anxiety, and an overview of most important studies examining the influence of LA on FL learning and performance. Next is an attempt to define Phonetics Learning Anxiety. The second part of the paper constitutes a report on the aforementioned study, in which the research methodology, participants, research questions and hypotheses, and instruments are thoroughly explained. The discussion of quantitative data is followed by conclusions, suggestions for further research, and brief practical implications.

\section{Theoretical background}

\subsection{The concept of anxiety}

In the early definitions of anxiety, it is found to be synonymous with the phenomenon of fear (Piechurska-Kuciel 2008). For example, Darwin (1965/1872) suggested that anxiety derived directly from the expectation of suffering, while Lewis (1970: 77) considered it to be "an emotional state, with the subjectively experienced quality of fear as a closely related emotion." Rathus (1987) defines anxiety as "a negative emotion characterised by persistent fear and dread" (cf. Piechurska-Kuciel 2008: 27).

In modern psychology, anxiety is perceived as an unpleasant feeling that, unlike fear, may lack a direct source from the outside world. Friedman and Bendas-Jacob (1997: 1035) define anxiety as "a sense of discomfort and worry regarding an undefined threat," which may have not only a physical and physiological nature, but also be related to one's more or less conscious anticipation of his/her self-concept being damaged by "internal, real or imagined dangers" (Lesse 1988: 332). Finally, as contemporary psychologists explain, the difference between fear and anxiety lies in the defensive behaviors evoked by situations or stimuli considered dangerous. While in the case of fear, moving away from the threat ("active avoidance or fleeing") is usually observed, anxiety may lead an individual towards the danger ("approach or fighting") or to 
"withholding entering the dangerous situation (passive avoidance or freezing)" (Piechurska-Kuciel 2008: 28). This feature of anxiety differentiating it from fear is emphasized by Riskind et al. (2000: 873), who depict anxiety as "an anticipatory state of active preparation for dealing with threat."

Contemporary psychologists (e.g. Pekrun 1992; Vasa and Pine 2004) usually describe anxiety as a construct consisting of three components, i.e. cognitive, physiological and behavioural. The former refers to how individuals approach and process situations, information and stimuli that they consider threatening (e.g. RuizCaballero and Bermudez 1997). According to Pekrun (1992), anxiety arises when events are appraised as threatening and one's capacity of dealing with them as poor. Furthermore, anxiety is said to lead to several easily observable negative physiological/somatic symptoms. Many of them are caused directly by hormonal changes, which "lead to motor tension that can be observed in shakiness, jitteriness, muscle aches, inability to relax, fidgeting and restlessness" (Piechurska-Kuciel 2008: 29 after Wade and Tavris 1990). Additionally, anxiety may result in the feeling of panic, which reveals itself in different ways depending upon the individual, e.g. in chills, heart pounding, dry mouth, clammy hands or dizziness, just to mention a few (Scovel 1991). Symptoms of bodily tension, such as self-touching, closed body positions or leaning away can also be observed in anxious individuals (Burgoon and Koper 1984). The third component of anxiety - behavioral - reveals itself in irritability, impatience and behaviours typical for avoiding threatening situations, such as withdrawal or task avoidance (Kennerly 1990).

When discussing the construct of anxiety in the context of learning, it seems most vital to explain how it affects cognitive processing. First of all, observations prove that it leads to easy distraction, problems with concentration, limited creativity, increased response rate at the expense of accuracy, and reduced short-term memory capacities (Piechurska-Kuciel 2008). All these difficulties are related to the fact that anxiety causes attention narrowing and difficulties with attention control (e.g. Broadbent and Broadbent 1988). More specifically, cues and stimuli that automatically and intrusively draw the attention of an anxious person, pulling him/her away from the learning task, are those characterized by ambiguity, since they are perceived by him/her as potential sources of danger (Mathews et al. 1997). The constant process of scanning the learning material for stimuli and information considered threatening by the individual makes it difficult for him/her to focus on the proper task. As Eysenck (1997) clarifies, cognitive concern about one's performance (i.e. worry - one of the components of anxiety, next to emotionality) uses up cognitive resources required for storing and processing information, handicapping the attentional capacities and disabling effective handling of tasks, particularly those heavily dependent on storage and processing resources. Moreover, anxiety is said to interfere with information processing at all three levels, i.e. input, central processing and output stages (Piechurska-Kuciel 2008). In other words, an anxious learner will reveal difficulties with taking in, analyzing and retrieving new stimuli and information. Eysenck and Calvo (1992) further explain that anxiety causes ineffective functioning of the phonological loop responsible for temporary storage, and of the central executive coordinating the activity of the working memory. All these cognitive difficulties of an anxious person are said to inhibit his/her learning, making it less efficient, by demanding from him/her to put more effort than a low anxiety learner 
to attain the same results (Ashcraft and Kirk 2001; Mathews 1990). The arguments described above constitute the main principles of the interference models of anxiety.

\subsection{Language anxiety and its role in FL learning}

Although interest in affective factors as important determinants of learning can be observed in mid-20th century, it took a few more decades for the construct of anxiety to be more thoroughly examined in the field of SLA. After first attempts of defining anxiety in reference to FL learning, by transferring other types of anxiety into the FL learning context, a unique and specific concept of language anxiety (LA) and tool to measure it was proposed in 1986 by Horwitz, Horwitz and Cope. They characterize it is "a distinct complex of self-perceptions, beliefs, feelings, and behaviours related to classroom learning arising from the uniqueness of the language learning process" (Horwitz et al. 1986: 128). Furthermore, it is agreed that LA, i.e. "derogatory self-related cognitions..., feelings of apprehension, and physiological responses such as increased heart rate," can be experienced by FL learners both in academic and social contexts, in the situation of both learning and using the target language (TL) that has not been fully mastered (Gardner and MacIntyre 1993: 5).

As the Foreign Language Classroom Anxiety Scale (Horwitz et al. 1986) reveals, LA is said to be related to three other types of performance anxieties, i.e. communication apprehension, fear of negative evaluation and test anxiety. The first component refers to the "discomfort in talking in front of others ... caused by the belief in one's inability to express oneself fully or to understand what another person says" (Gregersen and Horwitz 2002: 562). Fear of negative evaluation is defined as "an apprehension about others' evaluations, avoidance of evaluative situations, and the expectation that others would evaluate [us] negatively" (Watson and Friend 1969: 450). Finally, the third type of anxiety considered to be connected to LA, i.e. test anxiety, though related specifically to the academic context of test taking, stems from the more general fear of failure caused by lack of certainty about one's ability or knowledge evaluated via tests.

Many studies have proven a negative correlation of moderate strength between LA and either course grades or outcomes on oral, vocabulary and grammar tests (e.g. Aida 1994; Bailey 1983; MacIntyre and Gardner 1989; Phillips 1992; Saito and Samimy 1996; Spielman and Radnofsky 2001). Some (e.g. MacIntyre 1999) even claim that LA is the strongest predictor of success in FL learning. As data of many studies show, the most anxiety-breeding skill is speaking, particularly when the oral task is to take place in front of other students. Moreover, the aspect that learners worry about most of all, being afraid of appearing ridiculous, is pronunciation (e.g. Phillips 1992; Price 1991; Young 1992).

Several types of language-specific anxieties have been identified, e.g. listening (comprehension) anxiety (Kim 2005; Vogely 1999), writing anxiety/apprehension (Cheng et al. 1999; Hilleson 1996), reading anxiety (Argamon and Abu-Rabia 2002; Saito et al. 1999), speaking anxiety (Woodrow 2006), or grammar anxiety (VanPatten and Glass 1999). However, so far no instrument has been designed to examine specifically the nature of pronunciation anxiety, which could address feelings evoked by 
the way one sounds or looks like when talking in a FL or worries experienced when learning/practising FL pronunciation.

Numerous studies in the field of LA have been devoted to identifying its causes. Young (1991: 427) posits the existence of "six potential sources of LA," such as personal and interpersonal anxieties, learner beliefs about FL learning, instructor beliefs about language teaching, instructor-learner interactions, classroom procedures, and language testing. From among them, it is personal and interpersonal anxieties, embracing self-perceptions of the FL learner/user, that have been the most frequently recognized (e.g. Bailey 1983; Gardner and MacIntyre 1993; Onwuegbuzie et al. 1999; PiechurskaKuciel 2008). The observation is supported by Krashen (1982, cf. Young 1991: 427), who states "the more I think about self-esteem, the more impressed I am with its impact. This is what causes anxiety in a lot of people." The important role of self-perceptions in the development of anxiety is also underlined by Young (1991: 427), who concludes: learners "with a self-perceived low ability level in a foreign or second language are the likeliest candidates for language anxiety."

There are data proving a significant systematic relationship between learners' perceived pronunciation level and their degree of LA and listening anxiety. In research conducted by Baran-Łucarz $(2011 ; 2013)$ a negative correlation of moderate strength was observed between students' FL pronunciation self-assessment and their LA level ( $\mathrm{r}=$ -.49 at $\mathrm{p}<.0005)$ and listening anxiety level $(\mathrm{r}=-.46$ at $\mathrm{p}<.005)$. In both cases the quantitative data pointing to the importance of pronunciation self-perceptions were further verified by responses of chosen subjects provided in semi-structured interviews.

\section{The model of Phonetics Learning Anxiety}

On the basis of the vast body of research conducted on anxiety and LA, a model of Phonetics Learning Anxiety (PhLA) has been proposed, hoping it may contribute to a better understanding of why some FL learners do not benefit as much as they could from a practical course of phonetics. PhLA may be defined as an apprehension experienced during a class of phonetics, evidenced by cognitive, physiological/somatic, and behavioral symptoms. Besides the general level of PhLA represented by the attitude towards the course of phonetics and the three observable types of reactions mentioned above, a few constructs underpinning the phenomenon of anxiety experienced during a practical course of phonetics are suggested. The proposed model of PhLA is depicted by Figure 1 below. 


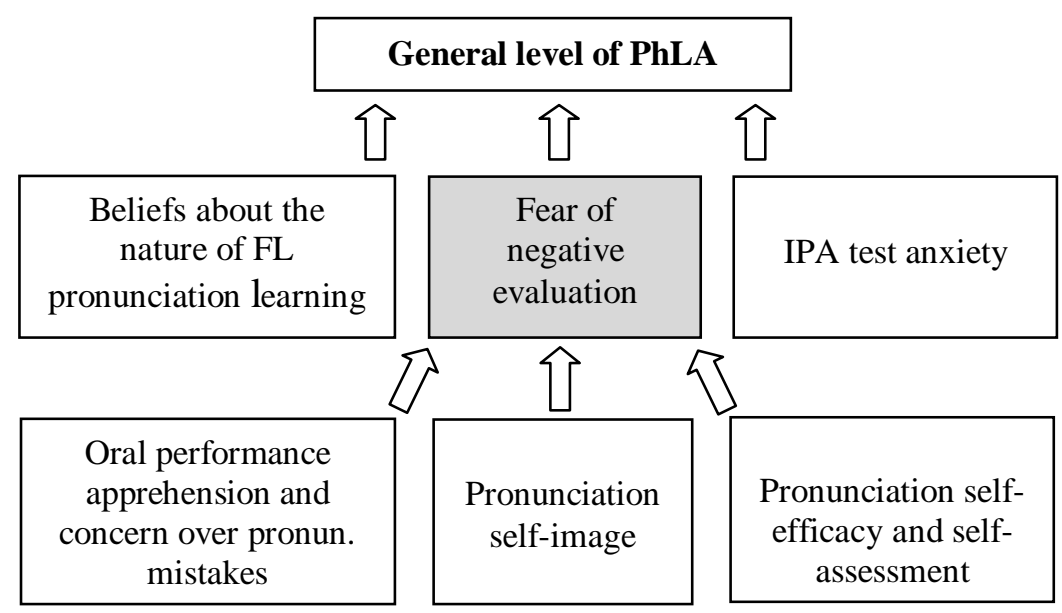

Figure 1. A hypothetical model of Phonetics Learning Anxiety

Relying on the outcomes of earlier studies on language anxiety, it is posited that the most important correlate/subcomponent of PhLA is the fear of negative evaluation. This construct, in turn, is assumed to be shaped by three relatively independent factors, i.e. general apprehension about oral performance and concern over FL pronunciation mistakes, pronunciation self-image related to one's appearance (the way one thinks he/she looks and sounds like) when speaking in a FL and acceptance of the perceived self-image, and finally pronunciation self-efficacy and self-assessment, i.e. beliefs about one's abilities needed to master a FL pronunciation and one's perceived level of pronunciation, both estimated usually in reference to other classmates. Next to the fear of being negatively evaluated, it is also beliefs about the nature of FL pronunciation learning and anxiety caused by transcription tests that have been assumed to determine the learners' feeling of apprehension during phonetics classes.

\section{The study}

\subsection{Research questions and hypotheses}

To find out whether PhLA significantly determines how much students benefit from a course of phonetics and to shed light on the nature of the construct, an empirical study has been carried out. The following main research questions and hypotheses were forwarded:

Q1: Does PhLA determine the learners' level of pronunciation measured after a course of phonetics? 
H1a: There is a significant negative relationship between the learners' degree of PhLA and their pronunciation level measured after a course of phonetics.

$\mathrm{H} 1 \mathrm{~b}$ : The pronunciation level measured after the course of phonetics is significantly lower in the case of students revealing high PhLA than in the case of students revealing low $\mathrm{PhLA}$.

Q2: What are the correlates/subcomponents of the PhLA?

H2a: There is a significant positive relationship between the learners' fear of negative evaluation and their level of PhLA.

$\mathrm{H} 2 \mathrm{a}_{1}$ : There is a significant positive relationship between the learners' degree of oral performance apprehension/concern over pronunciation mistakes and their level of PhLA.

$\mathrm{H} 2 \mathrm{a}_{\mathrm{II}}$ : There is a significant positive relationship between the learners' degree of negative pronunciation self-image and their level of PhLA.

$\mathrm{H}_{2} \mathrm{a}_{\mathrm{III}}$ : There is a significant positive relationship between the learners' degree of negative pronunciation self-efficacy/self-assessment and their level of PhLA.

$\mathrm{H} 2 \mathrm{~b}$ : There is a significant positive relationship between the learners' beliefs about the difficulty of FL pronunciation learning and their level of PhLA.

$\mathrm{H} 2 \mathrm{c}$ : There is a significant positive relationship between the learners' IPA test anxiety and their level of PhLA.

\subsection{Participants}

The research was carried out in two groups of first-year extramural students of the University of Wroclaw, majoring in English $(\mathrm{N}=32)$. Among the participants there were 10 males and 22 females. All of them were native speakers of Polish, aged 19-24. Having passed the extended level of the high school leaving examination in English (Matura) with a score of at least $70 \%$, they mostly represented an upper-intermediate level (B2), though some seemed better than the others (C1). None of the participants had spent more than three months in an English-speaking country. Before starting university education most of them were taught by Polish teachers of English who limited pronunciation practice of their students to repetition of new words and correction of mispronunciations.

At the time the data for the study were being collected, the subjects were just finishing their practical course of phonetics (altogether approximately thirty 90-minute lessons). All of them were either highly $(19 \%)$ or very highly $(81 \%)$ motivated to achieve a native-like level of pronunciation. When the model of English pronunciation is concerned, $88 \%$ declared they were more attracted to Received Pronunciation (RP), while the remaining $12 \%$ chose General American (GA) as the norm to approximate. 


\subsection{Description of the phonetics course}

The phonetics classes were predominantly practical, since the aim of the course was to help students improve their pronunciation habits rather than to raise their theoretical knowledge on complex phonetic and phonological issues. While the second year of phonetics in our institute focuses more on suprasegmentals, pronunciation at lexical level and further remedy work, the first year is devoted mainly to practising the articulation of segments, word stress and most important aspects of connected speech (weak forms, assimilations, elisions, linkings).

Before the practical part of each lesson began, the new sound was introduced, i.e. its place and manner of articulation were provided by means of various techniques appealing to different modalities and senses of the students. In the theoretical part of the class the inductive approach was used, that is, the learners tried to observe and come up with their own hypotheses about how particular segments in English are pronounced and how they differ from Polish counterparts. The practical part of the lesson would usually start with a few exercises warming up the articulators, borrowed from speech pathology. What followed was repeating words and sentences in which the sound appeared in different contexts. Finally humorous dialogues were listened to and then read aloud in lockstep (i.e. as a whole group) and pairs. Sometimes after having practised reading with a friend, a student would read the text aloud to the rest of the group. The controlled tasks were supplemented with game-like activities from various sources, songs, and presentations of students. It is important to add that while the learners were practising reading dialogues in pairs, the teacher monitored their work, coming up to each pair and offering further help if needed. Any time a pronunciation deviated significantly from the correct version, the teacher advised how to position the articulators, modeled the proper form and encouraged repetition until the production approximated the proper articulation of the sound. When the learner showed discomfort and reluctance to articulate the segment or word after the teacher, he/she was encouraged to see the instructor after the class, so as to practise the difficult area of pronunciation individually, without the presence of other students. Additionally, about 15 minutes of each lesson were devoted to transcribing difficult vocabulary items, which the learners were required to know for the written tests taken approximately once a month.

As suggested above, the students were allowed to choose either RP or GA as their goal. Consequently, the features of the two norms were presented in a detailed manner in the first semester, and consistency in using one of them was required both in articulation and in written transcription tests.

\subsection{Instruments}

Three main instruments were designed for the purpose of this research, i.e. the Introductory Questionnaire, Phonetics Learning Anxiety Scale (PhLAS), Pronunciation Attainment Test (PAT), and IPA Tests. The major characteristics of the tools are presented thoroughly below. 


\subsubsection{Introductory Questionnaire}

The measure was a pen-and-pencil questionnaire that the students filled out during the first class of phonetics. It opened with a question about the participants' level of motivation to reach native-like pronunciation. It consisted in the students assessing their level of motivation by writing in a digit from 1 to 5 , representing the strength of their desire to speak with a native-like accent, where 1 meant 'I definitely do not want to speak with an English native-like accent', while 5 - 'I want to achieve native-like accent very much'. The remaining seven open questions enquired about the subjects' prior FL learning experience, e.g. about the intensity of learning, ways of having practised pronunciation during their FL courses and individually (autonomously), or about visits abroad. Moreover, the questionnaire required from the subjects to reflect on the difficulties they believed they had with English pronunciation.

The goal of applying the tool, besides getting to know my students better, was to control certain variables and exclude from the study, if necessary, those learners who stood out from the rest, e.g. had spent a longer period of time in an English-speaking country, or had regularly been provided with formal instruction on pronunciation and intensive practise in this FL aspect. However, the responses showed that data collected from all the students could be taken into account in the research.

\subsubsection{The Phonetics Learning Anxiety Scale}

The aim of PhLAS was to measure the anxiety level experienced during the course of phonetics and to verify the hypotheses $\mathrm{H} 2 \mathrm{a}-\mathrm{H} 2 \mathrm{c}$ concerning the proposed subcomponents/correlates of PhLA. The instrument had the form a self-report 44-item questionnaire based on a 6-point Likert scale, which required the testees to agree/disagree to various extent with the provided statements. Since it was intended to be distributed among students of Polish origin, the language of the instrument was Polish. The wording of 13 statements in the entire battery required a reversed scoring key to be used.

The first part of PhLAS, consisting of 15 items, was aimed at measuring the general level of PhLA without enquiring about the possible reasons for them feeling anxious. The higher the score the students obtained, the higher their general level of PhLA was considered to be. The items addressed the attitudes toward the course of phonetics and the typical symptoms testifying to the existence of anxiety. Below are examples of statements from each category.

\section{$\underline{\text { General level of PhLA (15 items) }}$}

- Items addressing the attitude towards the class of phonetics, e.g.:

1. I prefer other classes than that of phonetics.

12. Phonetics is one of my favourite classes. (reversed scoring)

- Items addressing cognitive symptoms of anxiety, e.g.:

7. I am so nervous that I can't hear the new sounds or word stress properly. 
8. While reading aloud I am so embarrassed that I can't focus on my pronunciation and control it.

- Items addressing somatic symptoms of anxiety, e.g.:

2. I feel more comfortable and less tense at most of the other courses.

10. Usually I feel relaxed at the phonetics class. (reversed scoring)

14. I feel relief when the class of phonetics is coming to an end.

- Items addressing behavioural symptoms of anxiety, e.g.:

4. I often volunteer during the classes of phonetics. (reversed scoring)

9. I would feel less anxious if the classes of phonetics had the form of individual training with the teacher.

13.If I didn't have to, I wouldn't attend the classes of phonetics.

The second part of the questionnaire consisted of items addressing concepts that were assumed to be important correlates/subcomponents of the PhLA construct. Consequently, statements referring to oral performance apprehension and concern for pronunciation mistakes, pronunciation self-image and self-efficacy/self-assessment, beliefs about the difficulty of FL pronunciation learning, and IPA test anxiety were formulated. Below are a few examples of the items.

Fear of negative evaluation (20 items)

- Items addressing oral performance apprehension and concern over pronunciation mistakes (10 items), e.g.:

16.I feel my heart pounding when the teacher corrects my pronunciation in lockstep.

20. I don't like to read aloud in front of the whole class.

17. I am not bothered about the pronunciation mistakes I make. (reversed scoring)

29. I feel tense and uneasy knowing that other students are listening to me reading or repeating sth. in English.

36. I feel more embarrassed committing a pronunciation mistake than any other type of mistake.

- Items addressing pronunciation self-image (6 items), e.g.:

33. I like to talk or sing to myself in English. (reversed scoring)

37. I think I sound ridiculous pronouncing English sounds and words the way they should be pronounced.

44. It seems to me that I sound terrible when I pronounce English sounds and words 'in the Polish manner'.

35. I don't like listening to myself reading aloud or speaking in English.

- Items addressing pronunciation self-efficacy and self-assessment (4 items), e.g.:

18. I find it more difficult to improve my pronunciation than other aspect/skills of English.

34. I don't have a talent to master FL pronunciation.

39. Other students have a better pronunciation than I. 
41. I am satisfied with my pronunciation level. (reversed scoring)

Beliefs about the nature (difficulty) of FL pronunciation learning (4 items), e.g.:

29. The pronunciation of English is very difficult for Poles.

32. I think pronunciation is the easiest FL aspect to master. (reversed scoring)

IPA test anxiety (5 items), e.g.:

19. Phonetics classes would be enjoyable if there were no transcription tests.

23. I feel more stressed reading aloud than writing an IPA test.

31. Even if I am well-prepared to the test, I am so nervous writing it that I can't recall the transcription of many words.

As the examples of the items show, though they addressed particular correlates/subcomponents of PhLA, they were at the same time usually formulated from the perspective of the typical cognitive, somatic or behavioural symptoms of anxiety. The scoring key of this part of the PhLAS is analogous to the one used in the case of the general level of PhLA, i.e. the stronger the testees agreed with the statements, the more points they gained (with the exception of a few items in which a reversed scoring key was used) for particular correlates.

The main questionnaire (PhLAS) was followed by three additional questions. In the first one the testees were asked to self-assess their level of PhLA, by finishing the statement 'The level of discomfort/ uneasiness/anxiety/fear I experience during the classes of phonetics is usually...' with one of the provided options 'very high', 'high', 'rather high', 'rather low', 'low', 'very low'. The two proceeding open questions asked about (hypothetical) causes of their anxiety and suggestions on how it could be lowered. Due to space limitations, the analysis of these responses is to be offered in one of the forthcoming papers.

\subsubsection{The Pronunciation Attainment Test}

At the end of the one-year course of phonetics the students' pronunciation was assessed with the use of four oral tests. Although most of the evaluation took place during the actual performance, the testing was recorded by means of a voice recorder (SONY ICDUX300) and microphone, and then downloaded onto a personal computer, so as to make it possible to return to any fragment of the recording in case any doubts with assessment appeared.

The first two tests - Sentence Reading $\left(T_{1}\right)$ and Text Reading $\left(T_{2}\right)$ - were aimed at evaluating the participants' habits of pronouncing segments practised during the course. The former consisted in the participants reading sets of sentences, in each of which a particular consonant or vowel occurred several times in various positions (initial, internal, final). In the latter test the subjects were handed a text (taken from CelceMurcia et al. 2008: 398) that they could browse through quickly and then were asked to read aloud, knowing they would have to summarise it. The idea of this procedure was to free the student from focusing on accuracy in pronunciation, by making them draw attention to meaning, and in this way to force them to rely on their pronunciation habits. 
In both tests an atomistic approach in assessment was used, with 0 to 3 points distributed for each segment depending on the frequency of producing it properly, i.e. as English native speakers do. The tasks were assumed to differ in the amount of monitoring and control they allowed for, with $T_{2}$ being less controllable than $T_{1}$. The overall score for Text Reading was additionally determined by word pronunciation and fluency in reading. Serious problems in these areas resulted in the students losing some points for $\mathrm{T}_{2}$. Additionally, Text Reading allowed to diagnose the subjects' consistency in using one of the accents - RP or GA.

The next two tests $-T_{3}$ and $T_{4}$ - consisted in the participants reading aloud lists of words. This time it is not pronunciation habits but word pronunciation that was assessed. One list $\left(\mathrm{L}_{1}\right)-\mathrm{T}_{3}-$ consisted of words that were practised during the course and appeared on transcription tests. The exact content of the list was not revealed to the participants. The other list $\left(\mathrm{L}_{2}\right)-\mathrm{T}_{4}-$ was well-known to the subjects. It consisted of words commonly mispronounced by Poles (based on Sobkowiak 1996). In the case of both tests, 1 point was given for each word properly pronounced.

\subsubsection{IPA Tests}

In this study results of four written tests taken by each subject during the second semester were taken into account and used for further analysis. The major part of each test consisted in transcribing 20 - 30 individual words using the International Phonetic Alphabet (IPA). For each word properly transcribed 3 points could be achieved. Every mistake, including misplacing or lack of the main stress, resulted in losing a point. The minimum result for passing the test was $70 \%$.

\subsubsection{Further assessment procedures}

Since all the tests constituted the basis for formal assessment of the students in the course of phonetics, the raw scores obtained by each learner were always transformed into grades. For further statistical analysis, the grades were changed into an 8-point interval scale, as Table 1 below displays.

\begin{tabular}{ll}
\hline \multicolumn{2}{l}{ GradesPoints } \\
\hline 2 & 1 \\
$3-$ & 2 \\
3 & 3 \\
$3+$ & 4 \\
4 & 5 \\
$4+$ & 6 \\
$5-$ & 7 \\
5 & 8 \\
\hline
\end{tabular}

Table 1. Transforming grades into points 


\subsection{Presentation and discussion of results}

\subsubsection{Descriptive statistics}

Having gathered all the necessary data with the batteries described above, descriptive statistics for the outcomes on the PhLAS, PAT and IPA Tests were computed (see Table 2 and Table 3 ).

\begin{tabular}{|c|c|c|c|c|c|c|c|c|c|}
\hline & \multirow{2}{*}{$\mathrm{T}_{1}(\mathrm{SR})$} & \multicolumn{2}{|c|}{$\mathrm{T}_{2}(\mathrm{PR})$} & \multirow{2}{*}{ Sum } & \multirow{2}{*}{$\mathrm{T}_{3}\left(\mathrm{~L}_{1}\right)$} & \multirow{2}{*}{$\mathrm{T}_{4}\left(\mathrm{~L}_{2}\right)$} & \multirow{2}{*}{ Sum } & \multirow{2}{*}{ Total } & \multirow{2}{*}{ IPA tests } \\
\hline & & Overall & $\mathrm{RP} / \mathrm{GA}$ & & & & & & \\
\hline Min-Max & $1-8$ & $1-8$ & $1-8$ & $3-24$ & $1-8$ & $1-8$ & 2-16 & $5-40$ & $4-32$ \\
\hline L-H & $1-8$ & $2-8$ & $3-8$ & $8-23$ & $1-7$ & $2-8$ & $3-15$ & $11-38$ & $4-29$ \\
\hline Mean & 4.75 & 4.91 & 5.72 & 15.38 & 3.53 & 5.34 & 8.88 & 24.25 & 13.29 \\
\hline Median & 5 & 5 & 6 & 16 & 4 & 5 & 9 & 24 & 13 \\
\hline SD & 1.98 & 1.75 & 1.57 & 4.9 & 1.54 & 1.66 & 2.8 & 7.26 & 6.6 \\
\hline
\end{tabular}

Table 2. Descriptive statistics for results of PAT

The figures in Table 2 imply that after the 45-hour course in phonetics focusing on practise of segments, word stress, weak forms, consistency in RP/GA and a few aspects of connected speech, there still is a lot of space for improvement in these areas of pronunciation. Unexpectedly, in the case of the less controllable test $\left(\mathrm{T}_{2}\right)$, the scores were not lower than in the case of the more controllable test $\left(T_{1}\right)$. This may suggest that the proper articulation of some of the elements of the English phonetic system have become automatic, but this cannot yet be advanced with any certainty. Among the possible explanations for such outcomes may be also the assessment of the samples. Despite the fact that the judge (the phonetics course teacher and, at the same time, the author of this paper) did her best to identify all the pronunciation errors that appeared in the text read by each subject and to use an objective atomistic approach to calculate the final scores, the assessment might have been less accurate (i.e. more lenient) than in the case of sentence reading $\left(\mathrm{T}_{1}\right)$.

The data indicate that students did better with the phonetic system than with pronunciation of difficult vocabulary items that appeared during the course. Finally, the results of the IPA tests reveal that many students have still difficulties with transcription. When the average PhLA level of all the participants is concerned, it appears to be relatively low (mean $=43.22 \mathrm{pts} ; \mathrm{min} / \max =15-90 \mathrm{pts}$; , with the bell curve shifted slightly more towards the lower scores (low-high $=31-60)$ 


\begin{tabular}{lr|rrr|rr}
\cline { 3 - 5 } & $\begin{array}{l}\text { General } \\
\text { level of } \\
\text { PhLA }\end{array}$ & \multicolumn{2}{|c|}{$\begin{array}{c}\text { Fear of negative evaluation } \\
\text { Opp/concern o. } \\
\text { apron. mist }\end{array}$} & $\begin{array}{c}\text { Pron. self- Pron. self- } \\
\text { image }\end{array}$ & $\begin{array}{c}\text { Beliefs } \\
\text { efficacy }\end{array}$ & $\begin{array}{c}\text { IPA } \\
\text { test anx }\end{array}$ \\
\hline Min-Max & $15-90$ & $10-60$ & $6-36$ & $4-24$ & $4-24$ & $5-30$ \\
L-H & $31-60$ & $26-50$ & $10-24$ & $6-18$ & $7-22$ & $13-29$ \\
Mean & 43.22 & 32.91 & 17.28 & 12.28 & 15.34 & 20.72 \\
Median & 42.5 & 33.0 & 17.0 & 12.5 & 15.0 & 21.5 \\
SD & 8.43 & 6.71 & 3.46 & 3.00 & 3.56 & 3.03 \\
\hline
\end{tabular}

Table 3. Descriptive statistics for results of PhLAS

The descriptive statistics in both tables show that all the assumptions (the scales, independence, linearity and normality assumptions) underlying Pearson correlation have been met, which allows us to proceed to further statistical analysis of data.

\subsubsection{Correlation analysis and t-test}

Table 4 displays the results of Pearson correlation computed between the general level of PhLA and outcomes for the subtests of the Pronunciation Attainment Test and for the IPA Tests. The same calculations have been made between the total scores on the PhLA and the measures of pronunciation

\begin{tabular}{|c|c|c|c|c|c|c|c|c|c|}
\hline & PAT & \multicolumn{4}{|c|}{ Pron. habits } & \multicolumn{3}{|c|}{ Word pron. } & \multirow{2}{*}{$\begin{array}{l}\text { IPA } \\
\text { tests }\end{array}$} \\
\hline & Total & $\mathrm{T}_{1}$ & $\mathrm{~T}_{2}$ & RP/GA & Sum & $\mathrm{T}_{3}\left(\mathrm{~L}_{1}\right)$ & $\mathrm{T}_{4}\left(\mathrm{~L}_{2}\right)$ & Sum & \\
\hline $\begin{array}{l}\text { General level } \\
\text { of PhLA }\end{array}$ & -.45 & -.38 & -.45 & -.36 & -.43 & -.30 & -.39 & -.44 & -.36 \\
\hline PhLA total & -.36 & -.36 & -.49 & -.23 & -.44 & -.18 & -.22 & -.23 & -.14 \\
\hline \multicolumn{10}{|l|}{$\mathrm{df}=30$} \\
\hline $\begin{array}{l}p<.05 \\
p<.025 \\
p<.01 \\
p<.005\end{array}$ & $\begin{array}{l}\text { rcrit }=.29 \\
\text { rcrit. }=.34 \\
\text { rcrit. }=.40 \\
\text { rctit. }=.44\end{array}$ & & & & & & & & \\
\hline
\end{tabular}

Table 4. Pearson product-moment correlation coefficients between the general level of PhLA, PhLA Total, and components of PAT and IPA test results

When the general level of PhLA is concerned, in all cases the relationship proved to be statistically significant of moderate strength, with the correlation between the Total for PAT $r=-.45$ at $\mathrm{p}<.005$, which allows to accept hypothesis H1a. The outcomes show that the relationship is stronger in the case of pronunciation habits than word pronunciation. The weakest relationship appeared between anxiety and the results on IPA tests. From 
among all the coefficients, the highest was achieved in the case of pronunciation measured in the less controllable reading test (T2). Consequently, it may be concluded that the higher the anxiety, the lower the level of automatic articulation. An explanation for this may lie in the cognitive effects of anxiety on learning and typical behavioral reactions of anxious learners, such as avoidance of practice in and outside classroom. When the PhLA total is concerned, a systematic relationship appeared only in the case of the acquired pronunciation habits. This phenomenon may be due to the statements addressing the correlates of phonetics learning anxiety being included in the PhLA total score. Their relation with the general level of PhLA is explained in the following section. To verify hypothesis $\mathrm{H} 1 \mathrm{~b}$, the subjects were categorized into two groups. Those who scored above the median for the general level of PhLA were considered the highly anxious subjects $(n=15)$, while those who scored below the median constituted the group of low PhLA learners $(n=16)$. After computing the means and SDs for the high and low PhLA participants, the $t$ values were calculated. The results are displayed in Table 5.

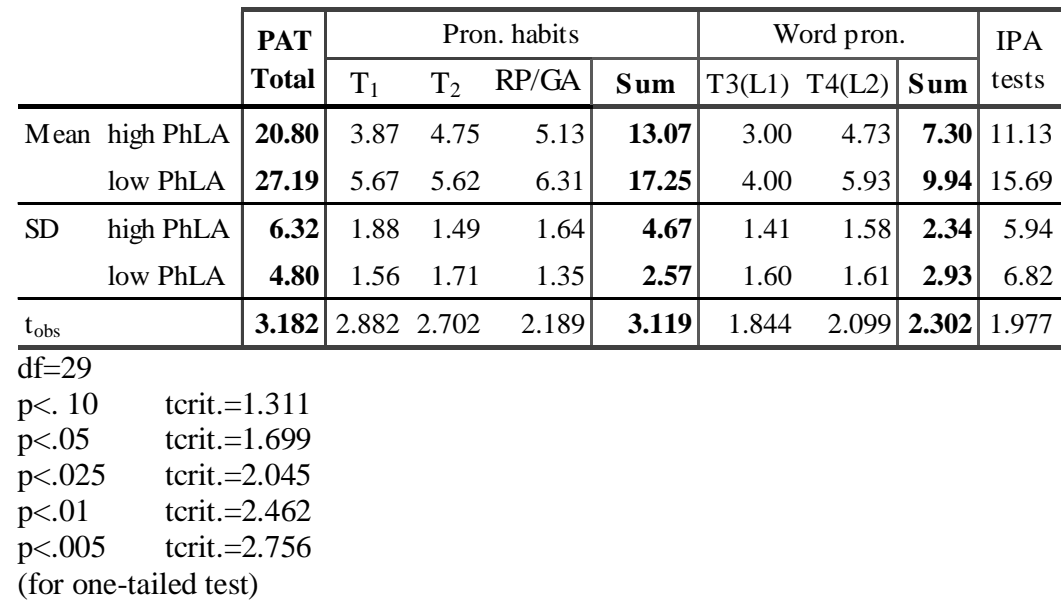

Table 5. Results of the independent t-test computed for components of PAT and IPA Tests

The outcomes showed the existence of a statistically significant difference between the pronunciation of high and low PhLA subjects. In each case, the scores obtained by the low anxiety subjects were higher than those of the high anxiety learners, which justifies the acceptance of hypothesis H1b. As in the case of correlation, the most meaningful results were found in the case of pronunciation habits rather than word pronunciation. The least meaningful difference between high and low PhLA scores, though still statistically significant, appeared in the case of IPA tests. 


\subsubsection{Correlates/subcomponents of the PhLA}

Having verified the presupposition about progress in pronunciation being related to the level of anxiety, the correlates of the construct could be determined. This was done by computing the Pearson product-moment correlation between the general level of PhLAS and each of the groups of items representing particular hypothetical correlates, i.e. oral performance apprehension (OPA)/concern over pronunciation mistakes (COPM), pronunciation self-image and self-efficacy/self-assessment, which altogether are assumed to constitute the fear of negative evaluation, beliefs about the nature of FL pronunciation learning, and IPA test anxiety. The results are presented in Table 6.

\begin{tabular}{lc|c}
\cline { 2 - 3 } & $\begin{array}{c}\text { General level of } \\
\text { PhLA }\end{array}$ & $\begin{array}{c}\text { Cronbach } \\
\text { alpha }\end{array}$ \\
\hline 1. Fear of neg. eval. & .82 & $.56 / .63$ \\
OPA/COPM & .65 & .77 \\
$\quad$ pron. self-image & .70 & $.46 / .70$ \\
$\quad$ pron. self-efifacy & .60 & .61 \\
2. Beliefs & .46 & .71 \\
3. IPA test anx & -.23 & .25 \\
\hline 4. General level of PhLA & 1 & .84 \\
5. PhLA Total & .78 & .87 \\
\hline $\mathrm{df}=30 \quad$ rcrit. $=.2960$ & & \\
p<.05 & & \\
p $<.005 \quad$ rctit.=.4487 & &
\end{tabular}

Table 6. Pearson product-moment coefficients between the general level of PhLA and correlates of the PhLAS; internal consistency of the general level of PhLA and its correlates

The outcomes show that PhLA is most strongly related to the fear of negative evaluation $(\mathrm{r}=.82)$, with all its components being significantly correlated with anxiety at a high level (from $\mathrm{r}=.60$ in the case of pronunciation self-efficacy/self-assessment to $\mathrm{r}=.70$ for pronunciation self-image). It is also the beliefs that are significantly related to the level of $\mathrm{PhLA}$, though at a moderate level $(\mathrm{r}=.46)$. However, no systematic relationship appeared between the general level of PhLA and IPA test anxiety.

Consequently, while hypotheses $\mathrm{H} 2 \mathrm{a}_{\mathrm{I}}-\mathrm{H} 2 \mathrm{a}_{\text {III }}$ and $\mathrm{H} 2 \mathrm{~b}$ can be accepted, hypothesis $\mathrm{H} 2 \mathrm{c}$ must be rejected. To examine the internal consistency of the whole 44-item PhLAS, its first part, measuring the general level of anxiety, and of each of the correlates/subcomponents of the construct, the Cronbach alpha was computed. The outcomes revealed high consistency in the case of the PhLAS Total (.87) and general level of PhLA (.84). However, when the items addressing particular correlates of PhLAS are concerned, not always were the coefficients at a satisfactory level. The low level of 
internal consistency and its negative direction in the case of IPA test anxiety might have resulted from the structure of a few statements in which the feeling of discomfort caused by IPA tests was contrasted with the fear connected with oral performance, e.g. '24. I prefer reading aloud to writing transcription tests'. Low internal consistency $(\mathrm{r}=.40)$ was also found in the case of pronunciation self-image. Such a result was caused by the last question, i.e. '44. I think I sound terrible pronouncing English sounds and words in the 'Polish manner', with which most of the students 'rather agreed' or 'agreed'. Excluding the statement raises the internal consistency of this subcomponent to .70 and of the fear of negative evaluation to 63 .

\subsubsection{Results of further observations}

Trying to have a closer look at how the responses of high and low anxiety participants differed, the mean answers for each item provided by the two groups were compared. Below is a table presenting some of the statements, in the case of which differences between the average responses of high and low anxiety students were observed. The average answers computed from the marked digits from 1 to 6 corresponded to the degree of agreeing/disagreeing with the statements.

The distribution of answers evidently shows a tendency for the feelings of low and high PhLA students to vary. For example, while the highly anxious participants are bothered by the fact that other students can hear them making pronunciation mistakes, the low PhLA students do not mind being assessed by their classmates (see statements 30 and 32). Moreover, interesting discrepancies may be observed in accepting oneself speaking Polglish (statement 44) and in considering oneself sounding ridiculous when trying to use proper English pronunciation (statements 37 and 38). As the average answers show, the low anxiety subjects seem to be more prone to accept their new 'selves' in the 'English shoes' than the high PhLA learners. Finally, it seems worth drawing attention to statement 39 , which reveals that low pronunciation self-assessment is more likely to be found among highly anxious students. 


\begin{tabular}{|c|c|c|}
\hline Item & $\begin{array}{l}\text { Low PhLA } \\
\quad(\mathbf{N}=16)\end{array}$ & $\begin{array}{l}\text { High PhLA } \\
\qquad(\mathbf{N}=15)\end{array}$ \\
\hline 3. I get nervous when I have to read aloud in English. & no & rather yes \\
\hline $\begin{array}{l}\text { 6. When I read aloud in English at the class of phonetics I } \\
\text { get so nervous that my performance is at a much lower } \\
\text { level than when I read aloud at home. }\end{array}$ & no & rather yes \\
\hline $\begin{array}{l}\text { 9. I would feel less stressed if the phonetics classes had the } \\
\text { form of individual meetings with the teacher. }\end{array}$ & no & yes \\
\hline 10. Usually I feel relaxed during the classes of phonetics. & yes & rather not \\
\hline $\begin{array}{l}\text { 11. I feel relaxed reading aloud during the classes of } \\
\text { phonetics. }\end{array}$ & rather yes & no \\
\hline $\begin{array}{l}\text { 15. When reading aloud I read fast so as to be freed from } \\
\text { the task as soon as possible. }\end{array}$ & no & rather yes \\
\hline $\begin{array}{l}\text { 28. I feel ashamed of myself in front of the teacher when } \\
\text { making the same pronunciation mistakes. }\end{array}$ & rather yes & rather not \\
\hline $\begin{array}{l}\text { 30. I feel nervous knowing that other students are listening } \\
\text { to me. }\end{array}$ & no & rather yes \\
\hline $\begin{array}{l}\text { 32. I'd rather my classmates did not hear me making } \\
\text { pronunciation mistakes. }\end{array}$ & rather not & yes \\
\hline 34. I prefer reading aloud to writing transcription tests. & rather yes & rather not \\
\hline $\begin{array}{l}\text { 36. I feel more embarrassed making a pronunciation } \\
\text { mistake than any other type of mistake. }\end{array}$ & rather not & rather yes \\
\hline $\begin{array}{l}\text { 37. I seems to me that I sound ridiculous/silly pronouncing } \\
\text { sounds and words the way they should be pronounced in } \\
\text { English. }\end{array}$ & no & rather yes \\
\hline $\begin{array}{l}\text { 38. I'm more prone to accept myself speaking English with } \\
\text { a Polish accent than trying to speak with a proper } \\
\text { (nativelike) English accent. }\end{array}$ & $\begin{array}{l}\text { definitely } \\
\text { not }\end{array}$ & rather not \\
\hline $\begin{array}{l}\text { 39. Other students have a much better pronunciation than } \\
\text { I. }\end{array}$ & rather not & rather yes \\
\hline $\begin{array}{l}\text { 44. I think I sound terrible pronouncing English sounds } \\
\text { and words in the 'Polish manner'. }\end{array}$ & yes & rather yes \\
\hline
\end{tabular}

Table 6. 'Average answers' of low and high PhLA participants to chosen items of the PhLAS

\section{Conclusions and further research directions}

The aim of this paper was to throw some light on the construct of phonetics learning anxiety and to examine whether it has an influence on how much students benefit from a course of phonetics. The results of the reported preliminary research show that PhLA is indeed an important factor determining success in FL pronunciation learning. A significant negative correlation of moderate strength $(\mathrm{r}=-.45$ at $\mathrm{p}<.005)$ was found between the level of PhLA and scores on the PAT. The relationship between the two variables appeared to be stronger in the case of pronunciation habits than word pronunciation. A connection was also observed between the PhLA and results of transcription tests, although the strength of relationship was weaker than in the case of PAT scores. The importance of PhLA in pronunciation learning has been also confirmed by t-tests, which proved the pronunciation measured by PAT and the ability to transcribe words using IPA to be at a significantly higher level in the case of low PhLA students 
than high PhLA learners. Moreover, the t-tests supported the fact that anxiety affects learning the FL phonetic system more than word pronunciation. This outcome can be further explained by results of examining the correlates of PhLA.

The strongest correlates/subcomponents of anxiety experienced during the course of phonetics were pronunciation self-image, referring to the way the learner believes he/she looks and sounds like when speaking a FL and whether he/she accepts his self-image, pronunciation self-efficacy and self-assessment and oral performance apprehension/concern over pronunciation mistakes. Together these factors, considered to result in the fear of negative evaluation, were strongly correlated with the level of anxiety accompanying pronunciation practice during a phonetics course $(\mathrm{r}=.82)$. The analysis of responses to particular items provided by high and low PhLA subjects lend support to the premise that the most important sources of anxiety belong to the group of students' self-perceptions, e.g. low pronunciation self-efficacy/self-assessment and negative pronunciation self-image, which presumably lead to the fear of negative evaluation. Such outcomes of the research go hand in hand with results of other studies (Young 1991) in which students' personal and interpersonal anxieties were observed to be most frequent causes of LA. Next to the fear of negative evaluation, it is also beliefs about the nature of FL pronunciation learning that revealed a moderate correlation between the level of PhLA ( $\mathrm{r}=.46$ at $\mathrm{p}<.005)$. Finally, the hypothetical model of PhLA assumed IPA test anxiety to be another subcomponent of PhLA. This, however, was not confirmed in the research.

A more thorough analysis of the results leads to the conclusion that problems with pronouncing the FL phonetic system (e.g. segments and aspects of connected speech) cause more anxiety than correctness of pronunciation at lexical level.

It needs to be emphasized that the ideas about the construct of phonetics learning anxiety presented in this paper are yet preliminary and that the reported outcomes of the empirical research ought to be viewed with utmost caution. Not only must the study be replicated among a larger group of students, but also both instruments require several amendments and validation. With respect to the PhLAS, changes need to be introduced, among others, to statements enquiring about IPA test anxiety, many of which demanded that the students estimate the fear connected with transcription tests in reference to oral performance apprehension. Moreover, since the use of IPA is an important part of most classes of phonetics, it seems worth substituting IPA test anxiety with a wider construct of transcription anxiety that would include both transcription practice and test anxiety. Additionally, what might be considered is adding or replacing some items with a few direct statements about experiencing fear of being negatively evaluated by other members of the class or the teacher. The battery diagnosing the participants' pronunciation can also be further worked on. Finally, the pronunciation scores would be undoubtedly more reliable if assessed by a few objective judges, preferably phoneticians sharing the same L1 as the subjects and native speakers.

Designing a valid and reliable tool measuring the level of anxiety experienced during a phonetics course and showing its sources could help phonetics instructors make the course less anxiety-breeding, and thus make it more effective. What could further aid in understanding the emotions accompanying FL phonetics learning is complementing the quantitative data with qualitative research consisting in, e.g. conducting semi-structured interviews with high and low PhLA students or gathering their reflections provided 
directly after phonetics classes on what made them anxious during the lesson, why and how the negative feelings could be reduced. Finally, an experiment can be carried out to verify empirically what indeed decreases the students' level of phonetics learning anxiety.

Despite the fact that the data achieved in this study need further verification, it may be suggested that certain aspects of teaching ought to be very carefully planned and controlled by the phonetics teacher. Among the areas worth being considered by the instructor are the following: classroom dynamics, teacher-student rapport, interaction patterns (group, pair, individual performance), manners of providing feedback, correction techniques, pace of work, goal-setting, strategy training and ways of raising self-perceptions of students. It seems that a sense of security during the lesson and a positive pronunciation self-image are necessary conditions for some learners to benefit from the practical course of phonetics.

\section{References}

Aida, Y. 1994. Examination of Horwitz, Horwitz, and Cope's construct of foreign language anxiety: The case of students of Japanese. The Modern Language Journal 78: $155-168$.

Argamon, O. and S. Abu-Rabia. 2002. The influence of language anxiety on English reading and writing tasks among native Hebrew speakers. Language, Culture and Curriculum 15: 143-160.

Ashcraft, M. H. and E. P. Kirk. 2001. The relationship among working memory, math anxiety and performance. Journal of Experimental Psychology: General 130: 224237.

Bailey, K. M. 1983. Competitiveness and anxiety in adult second language learning: Looking at and through the diary studies. In H. W. Seliger and M. H. Long (eds) Classroom Oriented Research in Second Language Acquisition. Rowley, MA: Newbury House: 67-103.

Baran-Łucarz, M. 2011. The relationship between language anxiety and the actual and perceived levels of FL pronunciation. Studies in Second Language Learning and Teaching 1(4): 491-514.

Baran-Łucarz, M. 2013. Foreign language pronunciation and listening anxiety - a preliminary study. In E. Piechurska-Kuciel and E. Szymańska-Czaplak (eds) Language in Cognition and Affect, Second Language Learning and Teaching. Springer-Verlag Berlin Heidelberg: 1-20. DOI: 10.1007/978-3-642-35305-5_15.

Broadbent, d. E.and M. Broadbent. 1998. Anxiety and attentional bias: State and Trait. Cognition and Emotion 2: 165-183.

Burgoon, J. I. and R. J. Koper. 1984. Nonverbal; and relational communication associated with reticence. Human Communication 10: 601-626.

Celce-Murcia, M., D. Brinton, and J. Goodwin. 2000. Teaching Pronunciation. A Reference for Teachers of English to Speakers of Other Languages. Cambridge: Cambridge University Press.

Cheng, Y.-S, Horwitz, E. K. and D. L. Schallert. 1999. Language anxiety: Differentiating writing and speaking components. Language Learning 49: 417-446. 
Darwin, C. 1965/1872. The Expression of Emotions in Man and Animals. Chicago: University of Chicago Press.

Eysenck, M. W. 1997. Anxiety and Cognition: A Unified Theory. Hove: Psychology Press.

Eysenck, M. W. and M. G. Calvo. 1992. Anxiety and performance: The processing efficiency theory. Cognition and Emotion 6: 409-434.

Friedman, I. A. and O. Bendas-Jacob. 1997. Measuring perceived test anxiety in adolescents: A self-report scale. Education and Psychological Measurement 57: 1035-1047.

Gardner, R. C. and P. D. MacIntyre. 1993. A student's contribution to second-language learning. Part II: Affective variables. Language Teaching 26: 1-11.

Gregersen, T and E. K. Horwitz. 2002. Language learning and perfectionism: anxious and non-anxious language learners' reactions to their own oral performance. The Modern Language Journal 86(4): 562-570. DOI: 10.1111/1540-4781.00161.

Hilleson, M. 1996. 'I want to talk with them, but I don't want them to hear': An introspective study of second language anxiety in an English-medium school. In K. M. Bailey and D. Nunan (eds) Voices from the Language Classroom. Cambridge: Cambridge University Press: 248-277.

Horwitz, E. K. 1988. The beliefs about language learning of beginning university foreign language students. The Modern Language Journal 72: 283-294.

Horwitz, E. K. 2010. Research timeline. Foreign and second language anxiety. Language Teaching 43(2): 154-167. DOI:10.1017/S026144480 999036X

Horwitz, E. K., M. Horwitz and J. A. Cope. 1986. Foreign language classroom anxiety. The Modern Language Journal 70: 125-132.

Kennerly, H. 1990. Managing Anxiety. A Training Manual. Cary, NC, USA: Oxford University Press.

Kim, J. 2005. The reliability and validity of a foreign Language Learning Anxiety Scale. Korean Journal of English Language and Linguistics 5: 213-235.

Lesse, S. 1982. The relationship of anxiety to depression. American Journal of Psychotherapy 36: 332-349.

Lewis, A. 1970. The ambiguous word 'anxiety'. International Journal of Psychiatry 9: 62-79.

MacIntyre, P. D. 1999. Language anxiety: A review of the research for language teachers. In D. J. Young (ed) Affect in foreign language and second language learning. A practical guide to creating a low-anxiety classroom atmosphere. Boston: McGraw-Hill: 24-45.

MacIntyre, P. D. and R. C. Gardner. 1989. Anxiety and second language learning: Toward a theoretical clarification. Language Learning 39: 251-275.

Mathews, A. 1990. Why worry? The cognitive function of anxiety. Behavior Research and Therapy 28: 455-468.

Mathews, A., Mackintosh, B. and E. P. Fulcher. 1997. Cognitive biases in anxiety and attention to threat. Trends in Cognitive Sciences 1: 340-346.

Onwuegbuzie, A. J., Bailey, P. and C. E. Daley. 1999. Factors associated with foreign language anxiety. Applied Linguistics 20(2): 217-239. 
Pekrun, R. 1992. Expectancy-value theory of anxiety: Overview and implications. In D. Forgays and T. Sosnowski (eds) Anxiety: Recent Developments in Cognitive, Psychological and Health Research. Washington, DC: Hemisphere: 23-39.

Piechurska-Kuciel, E. 2008. Language Anxiety in Secondary Grammar School Students. Opole: Wydawnictwo Uniwersytetu Opolskiego.

Phillips, E. M. 1992. The effects of language anxiety on student's oral test performance and attitudes. The Modern Language Journal 76: 14-26.

Price, M. L. 1991. The subjective experience of foreign language anxiety: Interviews with highly anxious students. In E. K. Horwitz and D. J. Young (eds) Language Anxiety: From Theory and Research to Classroom Implications. Upper Saddle River, NJ: Prentice Hall: 101-108.

Rathus, S. A. 1987. Psychology. New York: CBS College Publishing.

Riskind, J. H., Williams, N. L., Gessner, T. L., Chrosniak, L. D. and J. M. Cortina. 2000. The looming maladaptive style: Anxiety danger and schematic processing. Journal of Personality and Social Psychology 79: 837-852.

Ruiz-Caballero, J. A. and J. Bermudez. 1997. Anxiety and attention: Is there an attentional bias for positive emotional stimuli? Journal of General Psychology 124: 194-211.

Saito, Y. and K. Samimy. 1996. Foreign language anxiety and language performance: A study of learner anxiety in beginning, intermediate, and advanced-level college student of Japanese. Foreign Language Annals 29: 239-248.

Saito, Y., Garza, T. J. And E. K. Horwitz. 1999. Foreign language reading anxiety. The Modern Language Journal 83: 202-218.

Scovel, T. 1991. The effect of affect on foreign language learning: A review of the anxiety research. In E. K. Horwitz and D. J. Young (eds) Language Anxiety: From Theory and Research to Classroom Implications. Upper Saddle River, NJ: Prentice Hall: 15-23.

Sobkowiak, W. 1996. English Phonetics for Poles. Poznań: Bene Nati.

Spielman, G. and M. L. Radnofsky. 2001. Learning language under tension. New directions from a qualitative study. The Modern Language Journal 85: 259-278.

VanPatten, B. and W. R. Glass. 1999. Grammar learning as a source of language anxiety: A discussion. In D. J. Young (ed) Affect in Foreign Language and Second Language Learning. A practical Guide to Creating a Low-anxiety Classroom Atmosphere. Boston: McGraw-Hill: 89-105.

Vasa, R. A. and D. S. Pine. 2004. Neurobiology in anxiety disorders in children and adolescents. In T. R. Morris and J. S. March (eds) Anxiety Disorders in Children and Adolescents. New York: Guilford Press: 3-26.

Vogely, A. 1999. Addressing listening comprehension anxiety. In D. J. Young (ed) Affect in Foreign and Second Language Learning. A Practical Guide to Creating a Low-anxiety Classroom Atmosphere. Boston: McGraw-Hill: 106-123.

Wade, C. and C. Tavris. 1990. Psychology. 2nd ed. New York: Harper \& Row.

Watson, D. and R. Friend. 1969. Measurement of social-evaluative anxiety. Journal of Consulting and Clinical Psychology 33: 448-457.

Woodrow, L. 2006. Anxiety and speaking English as a second language. Sage Publications 37(3): 308-328. DOI: 10.1177/00336882060 71315 
Young, D. J. 1991. Creating a low-anxiety classroom environment: What does the anxiety research suggest? The Modern Language Journal 75: 426-439.

Young, D. J. 1992. Language anxiety from the foreign language specialist's perspective: Interviews with Krashen, Omaggio Hadley, Terrell, and Rardin. Foreign Language Annals 25: 157-172. 